\title{
Interpretation of Healthy Diet Campaign in Healthy China Initiative 2019-2030
}

\author{
Liusen Wang'; Huijun Wang'; Zhihong Wang'; Hongru Jiang'; Weiyi Li ${ }^{1}$; \\ Shaoshunzi Wang'; Lixin Hao'; Bing Zhang'; Gangqiang Ding ${ }^{1,4}$
}

\section{Summary}

With the continuous development of the economy and agricultural modernization in the past three decades, nutritional deficiency issues in the Chinese population have been gradually improving. However, new nutritional and health challenges have emerged. Overweight and obesity, diabetes, cardiovascular diseases, and other chronic diseases have increasingly become major disease burden. In view of the problems above, the State Council released the Healthy China Initiative 2019-2030 focusing on 15 special campaigns and the Healthy Diet Campaign (HDC) as the second campaign. This article intends to interpret HDC in details including the following four aspects: background, major indices, strategies, and features. Healthy diet is the foundation of human health, and the HDC needs to be carried out together with other campaigns to achieve the overall goal of Healthy China.

\section{BACKGROUND}

At present, one in every nine people in the world is hungry, and one in every three is overweight or obese. More and more countries experience the double burden of malnutrition, where undernutrition coexists with overweight, obesity, and other diet-related noncommunicable diseases (NCDs) (1).

China also faces the similar problems that present serious challenges. Accompanying the acceleration of urbanization, industrialization, and population aging, people's lifestyles have changed dramatically. At the same time, there is still the issue of nutrition equity nationwide due to the vast territory, different eating habits, and uneven economic development in China.

It was reported that children aged below 6 years in the poor rural areas have the highest undernutrition prevalence resulting in $8.1 \%$ experiencing stunted, $2.5 \%$ experiencing being underweight, and $2.0 \%$ experiencing wasting in 2013. Although the anemia prevalence of children aged below 6 years was significantly decreased in comparison with 2002, $11.6 \%$ of children below 6 years still had anemia (2). On the other hand, the overweight and obesity prevalence of all age groups continued to rise. Overweight and obesity prevalence of children and adolescents aged 6-17 and the children aged below 6 years were $19.0 \%$ and $10.4 \%$, respectively (3).

In terms of Chinese residents' diet, the intake of animal food increased, but the intake of milk and dairy products was insufficient, and the consumption of oil, salt, and sugar was excessive. The intake of fat and protein is increasing, the level of vitamin intake is decreasing, and the intake of calcium is seriously insufficient (2). Good nutrition is an important component of healthy living. "Healthy Diet and Balanced Nutrition" is not only important for physical health but also has a significant impact on mental health.

In October 2016, the China Central Committee and the State Council jointly released the Healthy China 2030 Blueprint, which clearly defined the objectives and action plans. As an important strategy for the Chinese government to implement the UN 2030 sustainable development goals, the Healthy China 2030 Blueprint has been updated to a new milestone in China (4). On July 15, 2019, the State Council issued Healthy China Initiative 2019-2030 (5). With a focus on disease prevention and health promotion, the initiative proposed 15 special campaigns covering 3 aspects of "intervention of health-related risk factors, protection of full-life-cycle health, and prevention and control of major diseases." The HDC, 1 of the 15 specific campaigns, plays a key role of diet in health promotion.

\section{KEY CONTENT \& TARGETS}

HDC focuses on nutrition interventions for residents in poor areas, infants and young children, students, pregnant women, the elderly, and people with chronic diseases. The main places of nutrition 
intervention are restaurants and canteens (cafeterias), families, food industries, schools, and communities.

HDC proposes four outcome indices including the growth rate of adult obesity, the awareness rate of nutrition and health knowledge of residents, the anemia prevalence of pregnant women, and the stunting prevalence of children under 5 years old. All of those are listed in Table 1. Seven advocacy indices were proposed by HDC, as listed in Table 2. In addition, HDC also sets index for governments. It requires one nutrition instructor (a person who could provide healthy diet and balanced nutrition guidance to the residents) per 10,000 people.

\section{STRATEGIES}

To implement this ambitious policy, we must unite people and their communities with healthcare professionals, scientists, industries, and policymakers. Therefore, the strategies were created for three levels: individual and household, societal, and governmental.

At the individual and household level, the strategies were set for different groups of people. For the general population, it is suggested to eat a variety of foods (more than 12 kinds per day and more than 25 kinds per week), limiting fatty meats, smoked and pickled meats, high-salt and fried foods, as well as the intake of added sugar. For overweight and obese adults, it is recommended to control the total energy intake, increase the intake of vegetables and fruits, moderate the intake of quality protein, and reduce consumption of greasy foods, snacks, and sugary foods. For anemia, wasting, or other undernutrition population, it is suggested to increase the intakes of lean meat, milk and eggs, soybean and bean products appropriately and maintain food diversity. It is better to increase the intake of iron-containing foods or take iron supplements under the guidance of your doctor. For pregnant and lactating women, it is recommended to learn and practice nutrition and health knowledge. Pregnant women should often eat foods which rich in iron, increase consumption of animal food products and seafood rich in high-quality protein and vitamin $\mathrm{A}$, and choose iodized salt for adequate intake of iron, iodine, and folic acid during pregnancy. For the household, it is recommended to buy foods according to their needs; store the foods properly; choose fresh, hygienic, and seasonal food; adopt appropriate cooking methods; learn to read food labels; as well as dine at home.

There are five strategies at the societal level. First, the society as a whole should be encouraged to make joint efforts to promote the normalization of nutrition popularization and education activities. Second, nutrition and health practitioners should strengthen the guidance of nutrition label knowledge to food

TABLE 1. Outcome indices proposed by Healthy Diet Campaign (HDC) of Healthy China Initiative (2019-2030) in 2019.

\begin{tabular}{|c|c|c|c|}
\hline \multirow{2}{*}{ Outcome indices } & \multirow{2}{*}{ Base line } & \multicolumn{2}{|c|}{ Target date } \\
\hline & & 2022 & 2030 \\
\hline 1. Growth rate of adult obesity (\%) & $\begin{array}{l}\text { From } 2002 \text { to } 2012 \text {, the average annual } \\
\text { growth rate was about } 5.3 \%\end{array}$ & Continuously slow down & \\
\hline $\begin{array}{l}\text { 2. The awareness prevalence of nutrition } \\
\text { and health knowledge of residents }\end{array}$ & - & $10 \%$ more than in 2019 & $10 \%$ more than in 2022 \\
\hline 3. The anemia prevalence of pregnant women & $17.2 \%$ in 2013 & $<14 \%$ & $<10 \%$ \\
\hline $\begin{array}{l}\text { 4. The stunting prevalence of children under } \\
5 \text { years old }\end{array}$ & $8.1 \%$ in 2013 & $<7 \%$ & $<5 \%$ \\
\hline
\end{tabular}

TABLE 2. Advocacy indices proposed by Healthy Diet Campaign (HDC) of Healthy China Initiative (2019-2030) in 2019.

\begin{tabular}{lll}
\hline \multicolumn{1}{c}{ Advocacy indices } & \multicolumn{1}{c}{ Base line } & Target \\
\hline 1. Average daily salt intake per person $(\mathrm{g})$ & 10.5 in 2012 & $\leq 5$ \\
2. Average daily edible oil intake per person (g) & 42.1 in 2012 & $25-30$ \\
3. Average daily added sugars intake per person (g) & 30 in 2017 & $\leq 25$ \\
4. Average daily vegetables and fruits intake per person (g) & 296 in 2012 & $\geq 500$ \\
5. Average daily types of food intake per person (g) & - & $\geq 12$ \\
6. Adults maintain a healthy weight & In 2012, the proportion of BMl in & $18.5 \leq \mathrm{BMl}<24$ \\
\hline
\end{tabular}

Abbreviation: $\mathrm{BMI}=$ body mass index. 
enterprises, guide consumers to correctly read nutrition labels, and improve the awareness rate on nutrition labels. Third, enterprises are encouraged to produce and sell low sodium salt and promote its use under the guidance of experts. Fourth, canteens and restaurants are encouraged to be equipped with full-time and parttime dietitians and regularly carry out relevant skills training and assessment for management and employees. Finally, collective meal units are required to formulate and implement nutrition operation specifications and carry out healthy canteen demonstration and healthy restaurant creation activities.

There are four strategies at the governmental level. First, relevant government departments should promote the implementation of the National Nutrition Plan (2017-2030) and provide nutrition and dietary guidance adjusted for local conditions, continually promote nutrition intervention in poor areas, and promote the Nutrition Improvement Program for Rural Compulsory Education Students. Second, the government should promote nutrition legislation and policy research, formulate and implement a dietitian system, strengthen clinical nutrition work, and standardize nutrition screening, evaluation, and treatment. Third, relevant departments should improve the food safety standard system, formulate nutrition and health standards based on food safety, and promote the construction of food nutrition standard system. The governments should promote the development of nutrition-oriented agriculture and food-processing industries, and promote the production and consumption of low-sugar or sugarfree foods. Fourth, it should speed up the revision of the general principles of nutrition labeling of prepackaged foods, increase the mandatory labeling of sugar such as sucrose to help consumers choose healthy foods quickly, explore the labeling of "sugar" in catering food, and study the packaging standards of oil, salt, and sugar.

\section{FEATURES}

First, HDC is a detailed dietary improvement guidance document covering the entire population for the full-life-cycle. Specific dietary guidelines and goals are given for overweight and obese people, malnourished people such as those with anemia and wasting, and pregnant women and infants. This fully reflects the precision medicine strategy. The establishment of outcome indices in stages is conducive to the gradual realization of healthy diet and the acceptance of residents.

Second, HDC advocates multilateral cooperation to promote nutritional health. Take "reducing salt, oil, and sugar" as an example. The government should formulate and implement relevant standards and stretch itself with the function of warning and marking. The social organization should strengthen the science popularization, education, and guidance to the society as a whole. It encourages and guides the nutritional transition of the food industry; the establishment and evaluation of healthy restaurants, healthy canteens, and nutrition in school; the formulation and implementation of nutritional operating norms for meals. In the household, it focusses on guiding the consumption behavior of families with low intakes of salt, sugar, and edible oil; appropriate cooking methods; and the use of saltlimiting spoons, oil-limiting pots, and other tools.

Third, HDC is closely linked to other health campaigns. HDC does not have independent effects on health status of residents. A balanced diet is the foundation of health and an important complement to the state of disease. For example, the implementation of the National Fitness Campaign requires adequate nutrition to provide the energy and nutrients needed. The prevention and treatment of chronic diseases also necessitates the adoption of different diets (including low-sodium diets, low-carbohydrate diets, etc.) according to different diseases (6). The occupational population in the Occupational Health Campaign needs special nutrient supplies as a special population (7).

\section{CHALLENGES \& PERSPECTIVE}

In the past three decades, China has made considerable efforts and achieved great accomplishments in working out the problem of nutritional deficiencies, especially in the fields of maternal and child nutrition and nutrition in poor areas. However, nutrition is still facing great challenges. There has been a dramatic increase in the incidence of chronic diseases caused by nutritional excess. It is the right time to implement the HDC to fight for the rising risk of nutrition-related chronic diseases and low awareness of nutrition and health knowledge among residents in poor areas (8-9).

The Healthy China Initiative 2019-2030 is a longterm ambitious plan covering knowledge popularization, fitness, tobacco control, mental health, 
and healthy environment promotion. HDC is the second major campaign aimed at comprehensive interventions for health-related nutritional risk factors. In addition, it is the basis for other campaigns to maintain health throughout the life cycle and to prevent and control major diseases. Although the current situation is still challenging, with the joint efforts of the individual and household, the society, and the government, the phased objectives and the ultimate goal of Healthy China will eventually be achieved.

doi: $10.46234 / \mathrm{ccdcw} 2021.092$

\# Corresponding author: Gangqiang Ding, dinggq@chinacdc.cn.

\footnotetext{
${ }^{1}$ National Institute for Nutrition and Health, Chinese Center for Disease Control and Prevention, Beijing, China.
}

Submitted: January 09, 2021; Accepted: March 02, 2021

\section{REFERENCES}

1. Development Initiatives. 2020 global nutrition report: action on equity to end malnutrition. 2020. https://globalnutritionreport.org/reports/ 2020-global-nutrition-report/. [2020-12-23].

2. Disease Control Prevention Bureau of National Health Family Planning
Commission. Report on Chinese residents' chronic diseases and nutrition 2015. Beijing (China): People's Medical Publishing House; 2015. http:// www.360doc.com/content/15/0704/21/15509478_482649075.shtml. [2020-12-24]. (In Chinese).

3. Healthy China. The State Council Information Office held a press conference on the "report on chinese residents' chronic diseases and nutrition 2020" (full text of the actual record). https://baijiahao. baidu.com/s?id=1686848982016233734\&wfrspider\&forpc. [2020-1223]. (In Chinese).

4. The Communist Party of China Central Committee the State Council. Healthy China 2030 blueprint. 2016. http://www.gov.cn/xinwen/201610/25/content_5124174.htm. [2020-12-23]. (In Chinese).

5. Health China Action Promotion Committee. Healthy China initiative (2019-2030). 2019. http://www.gov.cn/xinwen/2019-07/15/content_ 5409694.htm. [2020-12-23]. (In Chinese).

6. Abbate M, Gallardo-Alfaro L, del Mar Bibiloni M, Tur JA. Efficacy of dietary intervention or in combination with exercise on primary prevention of cardiovascular disease: a systematic review. Nutr Metab Cardiovasc Dis 2020;30(7):1080 - 93. http://dx.doi.org/10.1016/j. numecd.2020.02.020

7. Shrestha A, Karmacharya BM, Khudyakov P, Weber MB, Spiegelman D. Dietary interventions to prevent and manage diabetes in worksite settings: a meta-analysis. J Occup Health 2018;60(1):31 - 45. http://dx. doi.org/10.1539/joh.17-0121-RA.

8. He YN, Li YP, Yang XG, Hemler EC, Fang YH, Zhao LY, et al. The dietary transition and its association with cardiometabolic mortality among Chinese adults, 1982-2012: a cross-sectional population-based study. Lancet Diabetes Endocrinol 2019;7(7):540 - 8. http://dx.doi.org/ 10.1016/S2213-8587(19)30152-4.

9. Tan YW, Zhou YL, Xu YJ. The current status of nutrition literacy and evaluation tools. Chin J Prev Med 2020;54(10):1146 - 51. http://dx. doi.org/10.3760/cma.j.cn112150-20200401-00491. (In Chinese). 